\title{
TREND ANALYSIS SHOWS DECLINE OF AN ENDANGERED THERMOPHILIC SPRINGSNAIL (PYRGULOPSIS BRUNEAUENSIS) IN SOUTHWESTERN IDAHO
}

\author{
Cary D. Myler ${ }^{1}$, Greg C. Mladenka², and G. Wayne Minshall ${ }^{3}$
}

\begin{abstract}
Aвstract.-We analyzed population trend data during 1991-2004 for the Bruneau hot springsnail (Pyrgulopsis bruneauensis) from rangewide hot spring surveys completed along $4 \mathrm{~km}$ of Bruneau River. The objectives of this study were to analyze population trends and assess other measured parameters, such as water temperature, specific conductance, and groundwater decline, for changes that may influence population trends. We used simple linear regression to determine significant relationships between measured parameters. Total numbers of hot springs surveyed in the 4-km reach are declining at a rate of $\sim 5$ hot springs per year, and numbers of hot springs containing $P$. bruneauensis in the same reach are declining at a rate of 3.75 per year. We found that the decline of hot springs with and without $P$. bruneauensis was significantly related to the decline of the thermal aquifer which underlies this area.
\end{abstract}

Key words: Pyrgulopsis bruneauensis, Bruneau hot springsnail, endangered species, population trend, thermal springs.

Pyrgulopsis is the 2nd-largest genus of freshwater mollusks in North America, comprising over 120 described species (Hershler 1998). These tiny, gill-breathing gastropods (commonly known as springsnails) are obligately aquatic throughout their life cycle (Hershler and Sada 2002). The Bruneau hot springsnail (Pyrgulopsis bruneauensis, Hershler 1990) is distinguished by small size $(<2.8 \mathrm{~mm}$ shell height), a globose-low conical shell, and a penis with an elongate, muscular filament and a small lobe bearing a single distal glandular ridge (Hershler 1990). This species is endemic to thermal springs and seeps $\left(>11^{\circ} \mathrm{C}\right)$ along an $8-\mathrm{km}$ reach of Bruneau River in southwestern Idaho (Fig. 1) and typically resides in waters ranging from $11^{\circ} \mathrm{C}$ to $35^{\circ} \mathrm{C}$ (Mladenka 1992). The mode of dispersal for this species remains unknown, but 2 possible modes are crawling and seasonal drift when river temperatures are conducive. At present, P. bruneauensis is listed as a federally protected endangered species (USFWS 1998). Increased agricultural use of groundwater underlying the Bruneau area since the 1970s has resulted in a steady decrease in local water table levels (Berenbrock 1993). Historically (as evidenced by photographs), thermal springs were likely once so plentiful that
P. bruneauensis was able to migrate and colonize new locations or recolonize springs following localized population extinctions resulting from events such as scouring by the river. Also, original populations probably were not isolated, with individuals being able to move among adjacent springs. Because water table elevation has declined dramatically, much habitat previously inhabited by $P$. bruneauensis is dry, resulting in markedly reduced abundance and isolated populations. The reduction in habitat and isolation of populations limit the ability of $P$. bruneauensis to increase its numbers above its current endangered state (Myler 2000), although no verifying genetic analysis has been performed.

The objectives of this study were to (1) analyze population trends from hot spring surveys conducted in the area upstream of the Bruneau River-Hot Creek confluence, and (2) assess other measured parameters for changes that may influence population trends. Surveys of all hot springs in a $6.5-\mathrm{km}$ reach along Bruneau River, upstream and downstream of the confluence of Hot Creek, were conducted in 1991 (Mladenka 1992), 1993 (Mladenka and Minshall 1993), 1996 (Mladenka and Minshall 1996), 2003 (Mladenka and Minshall 2003),

\footnotetext{
${ }^{1}$ U.S. Fish and Wildlife Service, Eastern Idaho Field Office, 4425 Burley Drive, Suite A, Chubbuck, ID 83202. E-mail: cary_myler@fws.gov

2Idaho Department of Environmental Quality, 444 Hospital Way \#300, Pocatello, ID 83201.

${ }^{3}$ Stream Ecology Center, Department of Biological Sciences, Box 8007, Idaho State University, Pocatello, ID 83204.
} 


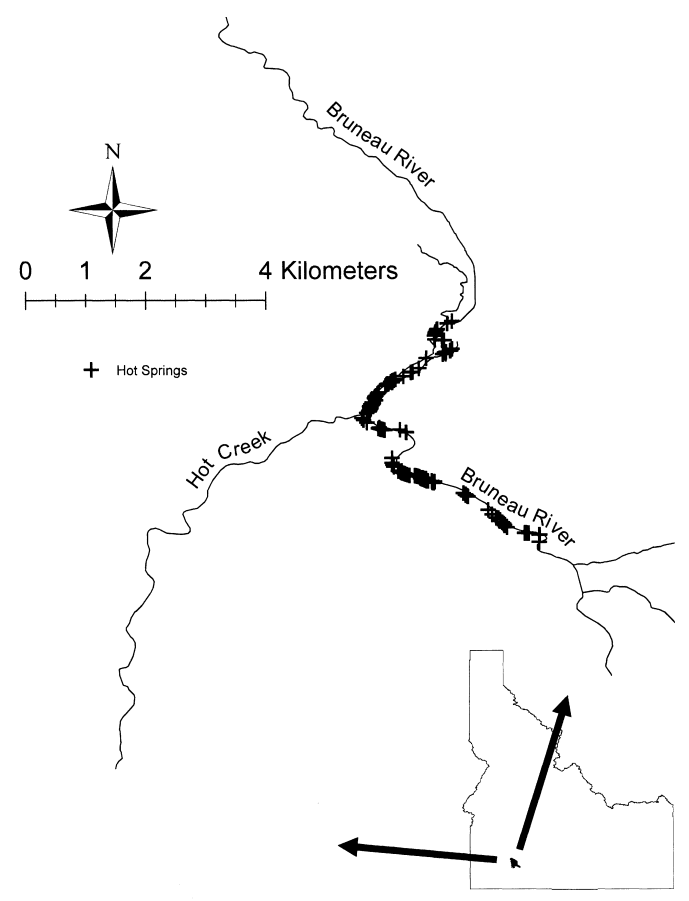

Fig. 1. Map of study location for Pyrgulopsis bruneauensis in Idaho. Flow direction of Bruneau River is north. Our study focused on hot springs that were upstream of the confluence of Hot Creek and Bruneau River.

and 2004 (Myler 2004). Additionally, hot springs upstream of the Hot Creek confluence were surveyed in 1998 (Myler and Minshall 1998), 2000 (Myler 2000b), and 2002 (Lysne 2002). Hot spring surveys upstream of Hot Creek were completed more frequently because hot springs in that reach are distinct and more surveys occurred there than downstream of Hot Creek, where many spring complexes are difficult to separate. This may have resulted in variation in the censuses; therefore, surveys conducted downstream of Hot Creek were removed from the analysis. Also, the 2002 survey was not included in this analysis because methods were not consistent with the other surveys.

\section{StUdy AREA}

Pyrgulopsis bruneauensis was located along an approximately $6.5-\mathrm{km}$ reach of Bruneau River (USGS 7.5-minute quadrangles: Hot Spring, Crowbar Gulch). This reach comprises the designated recovery area as described in the recovery plan for the Bruneau hot spring- snail (USFWS 2002). The recovery area is defined as the intersection of Bruneau River with the southern boundary of section 12, T08S, R06E, and continues downstream (including Hot Creek from its confluence with Bruneau River to Indian Bathtub) to the intersection of Bruneau River with the northern boundary of section 35, T07S, R06E, of Owyhee County, Idaho.

The survey area consisted of shoreline habitat on the east and west banks of Bruneau River upstream of Hot Creek. Pyrgulopsis bruneauensis habitat along Bruneau River consisted of geothermal spring seeps running through fractured basalt and cobble-boulder substrates mixed with fine sediments from both upland and riverine deposits. Geothermal spring seeps originating from the regional geothermal aquifer underlying the BruneauGrand View area of southwestern Idaho emerge from the ground (rheocrene habitats) or small basalt cliffs (madicolous habitats) and flow from several centimeters to several meters before reaching Bruneau River. Water temperatures of thermal spring habitats along Bruneau River and in Hot Creek range from approximately $11^{\circ} \mathrm{C}$ to over $40^{\circ} \mathrm{C}$. Riparian vegetation consists of grasses, sedges, forbs, poison ivy, narrow-leaf cottonwood, willow, hackberry, and occasional junipers.

\section{Methods}

During each survey (1991, 1993, 1996, 1998, 2000, 2003, and 2004), we systematically and intensively searched both banks of Bruneau River for geothermal springs or seeps. We carefully inspected each spring site for presence of $P$. bruneauensis and recorded its presence or absence. Relative density (high, medium, and low) was estimated based on the number of snails counted in a $60.8-\mathrm{cm}^{2}$ circle placed in the area of highest snail concentration in each spring, as described in Mladenka and Minshall (2001). Additional information collected included water temperature and specific conductance of geothermal spring seeps (YSI Model 30 temperature / specific conductance meter, Yellow Springs Instruments, Yellow Springs, $\mathrm{OH}$ ), habitat type (rheocrene or madicolous), and presence or absence of the exotic fish Tilapia zilli. Surveys of hot springs from all years were characterized as upper west (UW) or upper east (UE) in relation to their 
orientation to the confluence of Bruneau River and Hot Creek.

The U.S. Geological Survey (USGS) and the Idaho Department of Water Resources (IDWR) have monitored several groundwater wells near the P. bruneauensis recovery unit since 1991. Four wells near the confluence of Hot Creek were chosen for trend analysis for this project. Groundwater depths from wells were converted to elevations above sea level from surveyed elevations for each well. Data from all 4 wells were averaged for use in statistical comparisons with other measured parameters. Groundwater levels corresponding to specific dates of hot spring surveys were used for statistical analysis. The USGS maintains a flow monitoring station on Bruneau River just below the confluence of Hot Creek (USGS 13168500 Bruneau River near Hot Springs, ID). Daily flow data $\left(\mathrm{m}^{3} \cdot \mathrm{s}^{-1}\right)$ were retrieved for this location from 1991 to present. River levels for specific dates of each hot spring survey (1991-2004) were separated from the data set to determine if river level had any mathematical association with the number of hot springs located during surveys.

Relationships between total number of hot springs (with and without springsnails), specific conductance, hot spring temperature, groundwater elevation of the thermal aquifer, and surface water were analyzed using simple linear regression (SigmaPlot 8.0, SPSS, Chicago, IL, 2002). A Durbin-Watson statistic was used to test for serial autocorrelation between the residuals. The level of statistical significance for all analyses was set at $\alpha=0.05$.

\section{Results}

The total number of hot springs and total number of hot springs containing $P$. bruneauensis both declined over time $\left(r^{2}=0.97, P \leq\right.$ 0.001 and $r^{2}=0.91, P \leq 0.001$, respectively; Fig. 2A) and exhibited a significant positive relationship to each other $\left(r^{2}=0.92, P \leq\right.$ 0.001; Fig. 2D). Likewise, groundwater measurements, expressed as elevation of the thermal aquifer, declined over time $\left(r^{2}=0.80, P\right.$ $=0.006$; Fig. $2 \mathrm{~B}$ ). The total number of hot springs and total number of hot springs with $P$. bruneauensis both showed a positive relationship to thermal groundwater elevation $\left(r^{2}=\right.$ $0.72, P=0.016$ and $r^{2}=0.83, P=0.004$, respectively; Fig. 2C). Mean specific conduc- tance was positively correlated with the total number of hot springs $\left(r^{2}=0.94, P \leq 0.001\right.$; Fig. 2E), total number of hot springs with $P$. bruneauensis $\left(r^{2}=0.94, P \leq 0.001\right.$; Fig. $\left.2 \mathrm{E}\right)$, and elevation of thermal groundwater $\left(r^{2}=\right.$ $0.71, P=0.017$; Fig. $2 \mathrm{~F}$ ).

High and medium density sites along both the west banks and the east banks generally decreased in number over the study period (Figs. 3A, 3B). On the west bank, unoccupied hot springs also decreased during the study period, while sites with low snail densities showed an increasing trend (Fig. 3A). On the east bank, the number of low density sites peaked in 2000 and declined in 2003 and 2004 (Fig. 3B).

Groundwater elevation of the thermal aquifer near Hot Creek rises and falls in response to irrigation pump usage (Fig. 4). Average groundwater elevation near Hot Creek on days of the hot spring surveys dropped from $816.3 \mathrm{~m}$ in 1991 to $812.9 \mathrm{~m}$ in 2004 (Fig. 4). We did not find a significant relationship between groundwater elevation and hot spring temperature $\left(r^{2}=0.12, P=0.44\right)$. We also did not find any significant relationships between river discharge and total hot springs $\left(r^{2}=0.36\right.$, $P=0.154)$, hot springs with snails $\left(r^{2}=0.35\right.$, $P=0.162)$, groundwater elevation $\left(r^{2}=0.16\right.$, $P=0.374)$, hot spring water temperature $\left(r^{2}\right.$ $=0.00, P=0.99)$, or specific conductance $\left(r^{2}\right.$ $=0.49, P=0.08)$.

In the area upstream of Hot Creek on the west side of Bruneau River we found that average specific conductance remained constant among all sites ranging from 277 to 296 $\mu \mathrm{S} \cdot \mathrm{cm}^{-2}$ at $25^{\circ} \mathrm{C}$. However, upstream of Hot Creek on the east bank, much higher average specific conductance was observed in 1991$1996\left(367-457 \mu \mathrm{S} \cdot \mathrm{cm}^{-2}\right.$ at $\left.25^{\circ} \mathrm{C}\right)$ than in 1998 $2004\left(261-335 \mu \mathrm{S} \cdot \mathrm{cm}^{-2}\right.$ at $\left.25^{\circ} \mathrm{C}\right)$. We did not find any significant differences in average hot spring water temperature across survey years or when hot springs are separated into unoccupied, high-, medium-, or low-density sites.

\section{DisCussion}

Our data strongly suggest that the number of hot springs along Bruneau River upstream of Hot Creek is decreasing at a rate of 5 hot springs per year in response to decline of the geothermal Bruneau-Grand View aquifer that 

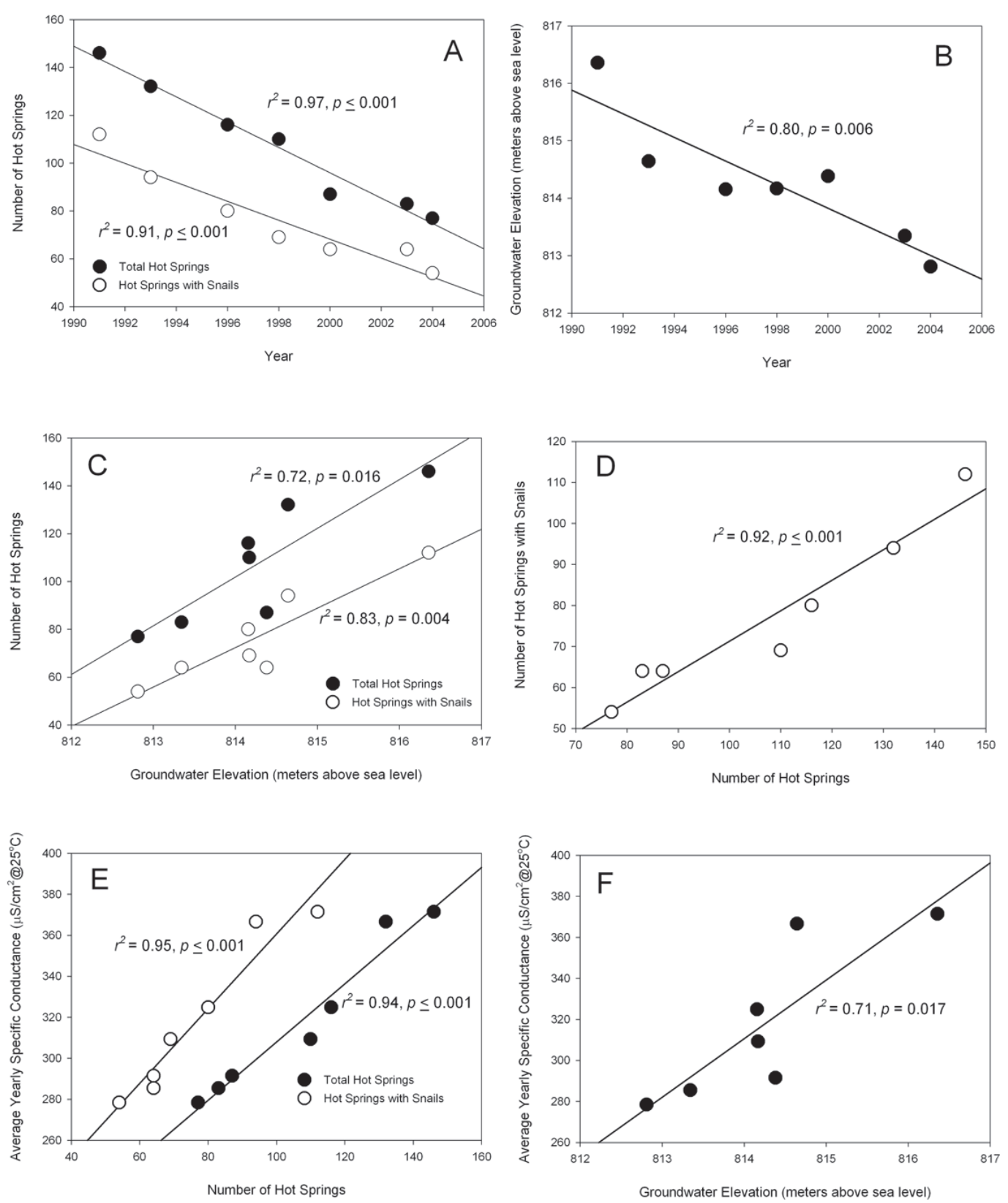

Fig. 2. Significant relationships between measured parameters using simple linear regression analysis for number of hot springs versus time (A), groundwater elevation versus time (B), number of hot springs versus groundwater elevation (C), number of hot springs with snails versus number of hot springs (D), specific conductance versus number of hot springs $(\mathrm{E})$, and specific conductance versus groundwater elevation $(\mathrm{F})$.

underlies this area. In addition, the numbers of hot springs upstream of Hot Creek on both sides of the river that contain high and medium springsnail densities are declining (Fig. 3A, 3B). We did not find any high-density sites in 2003 and only 2 in 2004. On the upper west bank there appears to be a slight increase in the number of low-density sites, but on the upper east bank the number of low-density sites generally increased until 2000, and those sites were much reduced in 2003 and 2004. The reduction of high- and medium-density sites 


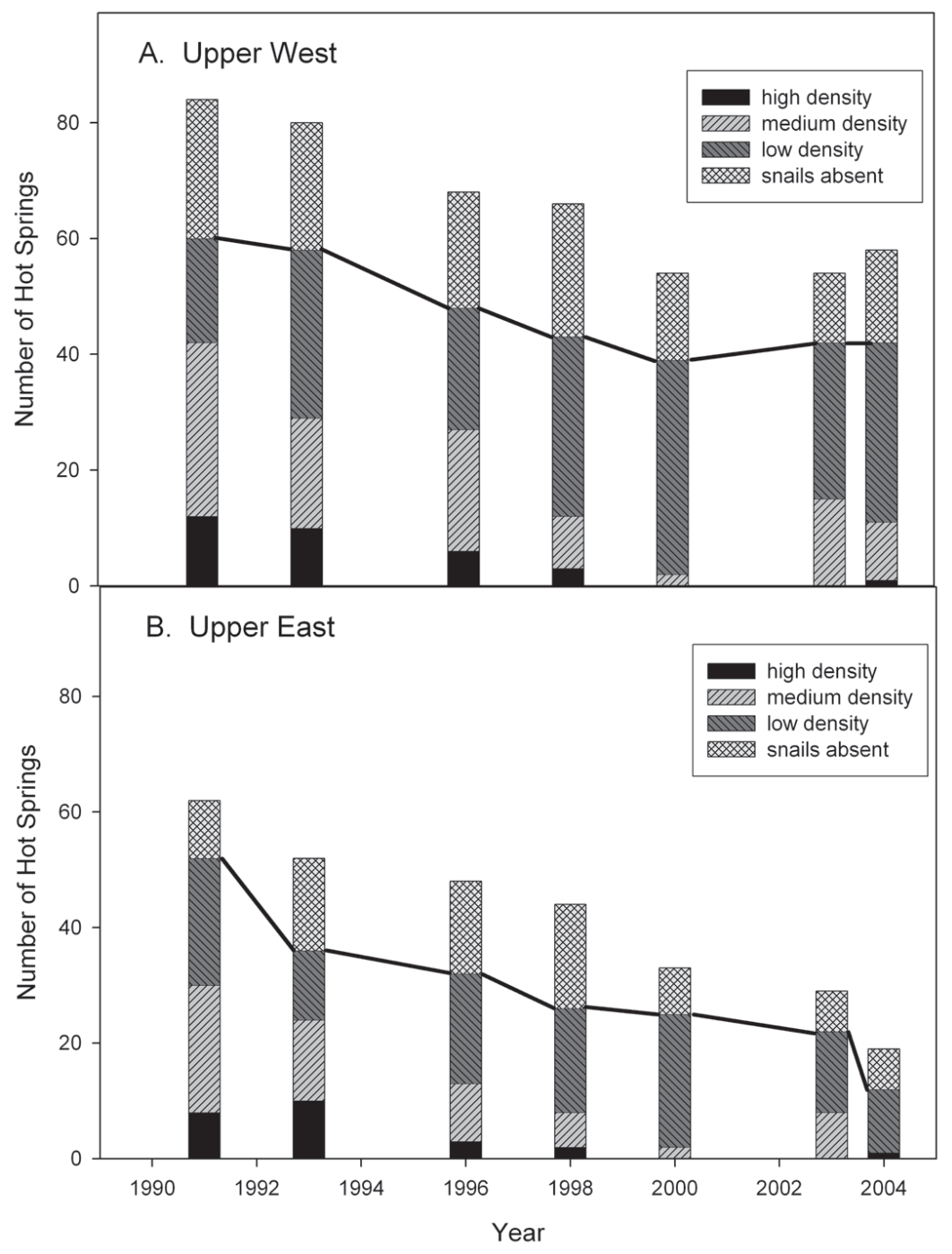

Fig. 3. Number of hot springs with respective relative densities of springsnails for hot springs located upstream of Hot Creek on the west side of Bruneau River (A), and downstream of Hot Creek on the east side of Bruneau River (B). Solid lines show the total number of springs with low, medium, and high densities of springsnails.

may pose additional problems for P. bruneauensis by limiting reproductive potential through lower densities of available mates, and by limiting recolonization of other lowdensity or unoccupied hot springs.

Specific conductance is a measure of the water's ionic activity and content at a specific temperature. In the hot springs upstream of Hot Creek, average specific conductance corresponds with declining groundwater elevation in the thermal aquifer $\left(r^{2}=0.71, P=\right.$ 0.017; Fig $2 \mathrm{~F}$ ), suggesting that the majority of the ions are coming from groundwater rather than from surface water of Bruneau River. Additionally, Mladenka (1992) investigated the tolerance of $P$. bruneauensis to a range of specific conductivities and found limited mortality at specific conductance levels below $62 \mu \mathrm{S}$ $\cdot \mathrm{cm}^{-2}$ at $25^{\circ} \mathrm{C}$. Therefore, significant positive relationships of specific conductance to total number of hot springs and total number of hot springs with springsnails suggest that $P$. bruneauensis populations are directly linked to groundwater from the thermal aquifer underlying this area. 


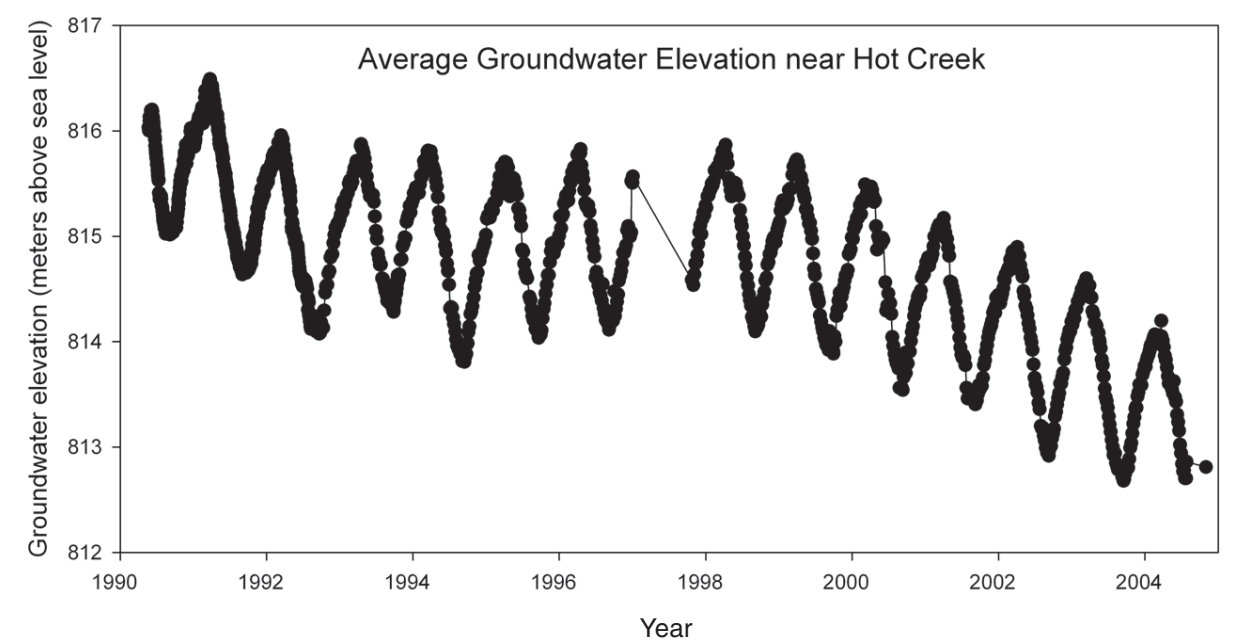

Fig. 4. Average groundwater elevation data from 4 wells near the confluence of Bruneau River and Hot Creek (USGS/IDWR unpublished data).

Although no significant relationships were shown between average hot spring temperature and any other parameter discussed in this study, a thermal water temperature tolerance $\left(11-35^{\circ} \mathrm{C}\right)$ has been shown in the laboratory by Mladenka (1992). We found that total number of hot springs with springsnails was significantly related $\left(r^{2}=0.92, P \leq 0.001\right)$ to the total number of hot springs (Fig. 2D), confirming our observations that this species is only found in areas influenced by thermal groundwater. These results corroborate with Mladenka's (1992) studies that directly link specific habitat needs of this species to thermal springs. If groundwater elevations continue to decline, at some point in time they will reach levels where hot springs no longer intercept the ground surface along Bruneau River upstream of the confluence of Hot Creek. Given that the elevation of the lowermost hot spring containing $P$. bruneauensis upstream of the confluence of Hot Creek is $781.5 \mathrm{~m}$, and given that the aquifer elevation $(810.8 \mathrm{~m})$ is declining at a rate of $0.3 \mathrm{~m} \cdot \mathrm{yr}^{-1}(1997-2004)$, we predict that if the decline in groundwater elevation continues at the present rate, the thermal springs upstream of Hot Creek will be completely dry within 24 years.

Although Myler (2000) found that P. bruneauensis readily exploits available geothermal habitat, the terrain upstream of Hot Creek is a geologically constrained bedrock canyon under little anthropogenic influence, suggesting that aquifer drawdown is the major threat in that area. Downstream of Hot Creek, the Bruneau River canyon widens into a floodplain and becomes increasingly influenced by surface water diversions, livestock, agriculture, and recreation. The river in this section is almost entirely dewatered during the irrigation season. Although P. bruneauensis lives in the hot springs that flow into the river channel, this species faces the threat of the declining thermal water table as well as increased anthropogenic influence. However, it is not known how the springsnail will respond to poor water quality, sedimentation, livestock, and increased human influence. Our data indicate that as groundwater elevation continues to decline, increased hot spring fragmentation will occur resulting in further isolation of $P$. bruneauensis.

The geothermal aquifer upon which $P$. bruneauensis depends underlies Bruneau Valley and also Sugar Valley and Little Valley. An unpublished USGS report (2004) indicates that the majority $(>60 \%)$ of thermal water removed from the geothermal aquifer is being pumped from Little Valley. IDWR monitors levels of the thermal aquifer in all 3 valleys, and similar declines in aquifer level are seen in Sugar Valley and Little Valley, as well as in Bruneau Valley. Agricultural pumping in all 3 valleys is the major cause of decline in hot springs available for P. bruneauensis upstream of Hot Creek (Berenbrock 1993). We know of no other species that are affected by the decline of this thermal 
aquifer but detailed surveys for organisms other than snails have not been conducted.

\section{RECOMMENDATIONS FOR MANAGERS}

In spite of the current political climate in which water rights litigation abounds, the time is at hand for federal and state agencies to work cooperatively with private landowners to create conservation easements and partnerships to reduce the amount of thermal groundwater that is pumped for agriculture. While the thermal aquifer may never completely recover to pre-European settlement conditions, stabilization of the aquifer at pre-2000 levels is paramount to the survival of this species and will help ensure sustainable agricultural production in the area.

\section{ACKNOWLEDGMENTS}

We greatly appreciate assistance in the field from Steve Lysne, Jeri Wood, Ben Matibag, Amanda Rugenski, Dave Hopper, Wes Myler, and Jesse Schomberg. Funding for this research was provided by the U.S. Fish and Wildlife Service, Snake River Basin Field Office. We give special thanks to Teri Peterson, Idaho State University, for assistance with statistical analyses. This manuscript benefited from the thoughtful comments of Lawrence E. Stevens and 2 anonymous reviewers.

\section{Literature Cited}

Berenbrock, C. 1993. Effects of well discharge on hydraulic heads in and spring discharges from the geothermal aquifer system in the Bruneau area, Owyhee County, southwestern Idaho. U.S. Geologic Survey Water Resources Investigations Report 934001. $58 \mathrm{pp}$.

Hershler, R. 1998. A systematic review of the hydrobiid snails (Gastropoda: Rissooidea) of the Great Basin, western United States. Part I. Genus Pyrgulopsis. Veliger 41:1-132.

. 1990. Pyrgulopsis bruneauensis, a new springsnail (Gastropoda: Hydrobiidae) from the Snake River Plain, southern Idaho. Proceedings of the Biological Society of Washington 103:803-814.
Hershler, R., AND D.W. SADA. 2002. Biogeography of Great Basin aquatic snails of the genus Pyrgulopsis. Pages 255-276 in R. Hershler, D.B. Madsen, D.R. Currey, editors, Great Basin aquatic systems history. Smithsonian Contributions to Earth Sciences 33.

Lysne, S. 2002. Report on the re-survey of the Bruneau hot springsnail sites. Report to U.S. Fish and Wildlife Service, Boise, ID.

MladenKa, G.C. 1992. The ecological life history of the Bruneau hot springsnail (P. bruneauensis). Final report to the U.S. Fish and Wildlife Service, Boise Field Office, ID. $116 \mathrm{pp}$.

MladenKa, G.C., and G.W. Minshall. 1993. Report on the re-survey of the Bruneau hot springsnail sites. Report to U.S. Fish and Wildlife Service, Boise, ID. $13 \mathrm{pp}$.

. 1996. Report on the re-survey of the Bruneau hot springsnail sites. Report to U.S. Fish and Wildlife Service, Boise, ID. 18 pp.

. 2001. Variation in the life history and abundance of three populations of Bruneau hot springsnails $(P$. bruneauensis). Western North American Naturalist 61:204-212.

. 2003. Report on the re-survey of the Bruneau hot springsnail sites. Report to U.S. Fish and Wildlife Service, Boise, ID. 9 pp.

Myler, C.D. 2000. Habitat improvements for an endangered springsnail in southwest Idaho. Master's thesis. Idaho State University, Pocatello. 52 pp.

2000b. Report on the re-survey of the Bruneau hot springsnail sites. Report to U.S. Fish and Wildlife Service, Boise, ID. 12 pp.

. 2004. Report on the re-survey of the Bruneau hot springsnail sites. Report to U.S. Fish and Wildlife Service, Boise, ID. 14 pp.

Myler, C.D., And G.W. Minshall. 1998. Report on the re-survey of the Bruneau hot springsnail sites. Report to U.S. Fish and Wildlife Service, Boise, ID. $14 \mathrm{pp}$.

U.S. Fish and Wildlife SERvice. 1998. Endangered and threatened wildlife and plants; notice of determination to retain endangered status for the Bruneau hot springsnail in southwestern Idaho under the Endangered Species Act. Federal Register 63:3298132996.

. 2002. Recovery plan for the Bruneau hot springsnail (P. bruneauensis). Region 1, Portland, OR. 52 pp.

U.S. Geological Survey. 2004. Results of the hydrological monitoring program for groundwater levels in the Bruneau-Grand View area, southwest Idaho through the 2003 water year. Unpublished report. 17 pp.

Received 2 December 2005 Accepted 13 September 2006 